\title{
Molecular control of pluripotency and germ line competency in chicken embryonic stem cells
}

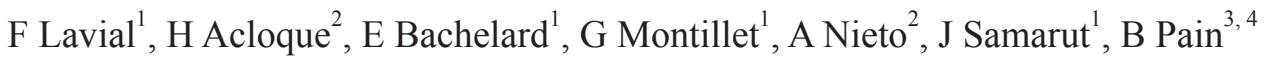 \\ ${ }^{1}$ Institut de Génomique Fonctionnelle, Université de Lyon, Ecole Normale Supérieure de Lyon, CNRS, INRA, Lyon, France; \\ ${ }^{2}$ Instituto de Neurociencias, San Juan de Alicante, Spain; ${ }^{3}$ Département de Physiologie Animale, INRA, France; ${ }^{4}$ Inserm, U384, \\ Clermont-Ferrand, France
}

Chicken Embryonic Stem cells (cESC) were isolated from the in vitro establishment of cultured blastodermal cells (cBC) derived from pregastrulating stage IX-XII chicken embryo (EG \& K) (Pain et al., 1996, Petitte et al., 2004). These cESC present typical features of embryonic stem cells (ESC) such self renewing and differentiation properties both in vitro and in vivo. The cells cESC have a strong potential of in vitro differentiation and can be induced in the three germ layer, the ectoderm, mesoderm and endoderm derivatives. In vivo, these cells can contribute to embryo morphogenesis all along early development. While the $\mathrm{CBC}$ were shown to contribute to the germ line once reinjected into recipient embryos (Carscience et al, 1993; Thoraval $e$ al, 1994), the ability of cESC to enter and differentiate into functional germ cells is still elusive and it appears that the establishment of in vitro culture of the cESC induces a loss of this competence germinal (Petitte et al, 2004; Van de Lavoir et al, 2005) which is maintained for the PGCs cells under conditions of particular cultures (Van de Lavoir et al, 2006).

We performed the first studies of the molecular characterization of the cells cESC, cBC and of the germinal cells. Our results indicate the maintenance and the relative losses of expression of certain genes characteristic of these various cellular types. In particular, the cells cESC express very strongly a set $f$ key genes which control pluripotency like cPouV, Nanog, Tra1, Gcnf, etc... We were the first to identify, clone and charaterise the role of such pluripotency associated genes in non mammalian species and in birds in particular (Lavial et al, 2007). Relationship between pluripotency and germ line competency will be also presented and discussed.

Cell Research (2008) 18:s106. doi: 10.1038/cr.2008.196; published online 4 August 2008

Correspondence: Bertrand Pain

E-mail: bepain@u-clermont1.fr

Dr B Pain graduated in 1990 at the Lyon University at the Ecole Normale Supérieure de Lyon. Working on hemopoietic progenitors he identified the in vitro self renewal property of chicken erythroid progenitors before continuing during his post doctoral stage at the Institute of Medical Science at the University of Tokyo. He joined the INRA Institute (National Institute for Agronomic Research) in 1992 where he established the in vitro chicken Embryonic Stem Cells (cESC) system. In 1999, he joined the Vivalis biotech company as R\& D Director and developed the two main company activities i) use of these cESC for vaccine production and ii) genetic modification of the cESC for production of therapeutical proteins. He is presently Director of Research at the INRA Institute and is developing genomic and functional approaches to decipher the molecular mechanisms controlling pluripotency and germ line competency of these cESC cells. He is co-authors of different publications and patents. 